\title{
The Lixiscope portable imaging device: an assessment of its use in the accident and emergency department
}

The Lixiscope portable imaging device (Fig. 1) was tested in the Accident and $\vec{\omega}$ Emergency Department of Northampton General Hospital for a period of 2 weeks. It was found to be an eminently suitable diagnostic tool for the accident and emergency department, producing substantial savings in patient waiting time and in the numbersi of X-rays ordered.

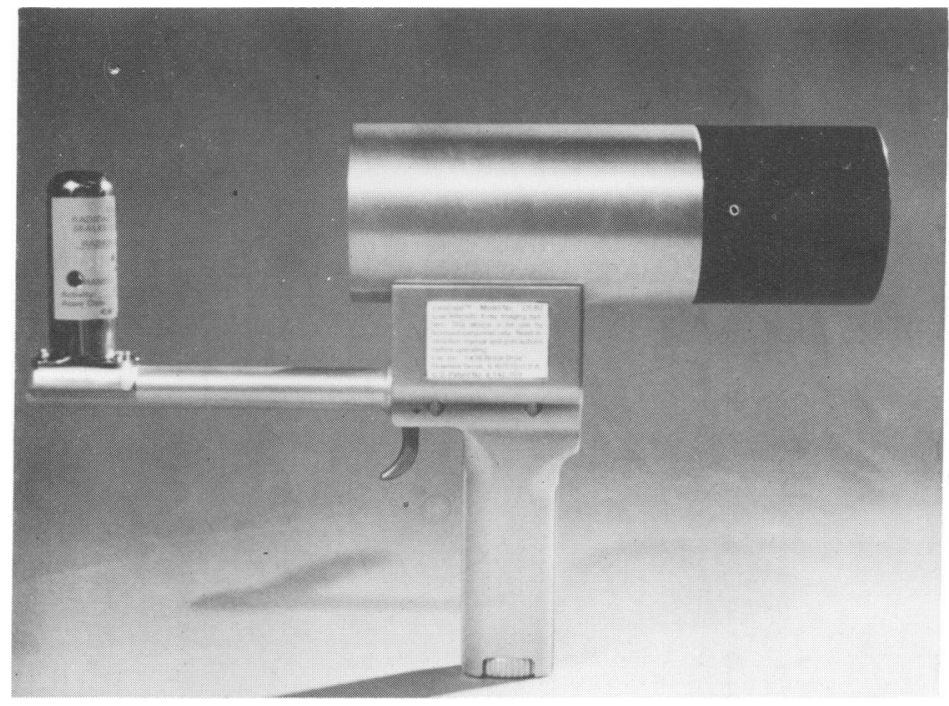

Fig. 1 The Lixiscope LSM-82-209 is available from Nuclear Data Incorporated, Rose Industrial Estate, 욱 Cores End Road, Bourne End, Bucks: Tel: Bourne End 22733. A floor-stand with foot activation and camera attachment are also available.

The Lixiscope is a hand-held X-ray imaging device using a shielded Iodine 1250 source. The aim of this study was to assess its potential for use in accident and emergency departments. The model used was the LSM-82-209 with a 10-cm aperture suitable for screening the hand, wrist, forearm, foot and ankle. The device weighs $6 \mathrm{lb} \$$ and currently retails at $£ 6250+£ 610$ for the Isotope source (both + VAT).

During the period of the trial the accident and emergency department treated 2392 
patients, of whom 854 (36\%) were X-rayed. A total of 118 patients were screened with the Lixiscope by the nine full-time medical staff (one consultant, one senior registrar and seven senior house officers). A questionnaire was completed for each patient screened. Safety precautions were established by the Medical Physics Department. The application of the device was left to the discretion and ingenuity of the medical staff. Screening was limited to one minute per patient (the device emits an audible bleep every 10 seconds) and potentially pregnant women were excluded.

\section{- Region screened (Table 1)}

No structure larger than the instrument's aperture could be screened and this was found to preclude an adequate examination of most adult ankles. Although the device's resolution (3.5-4.0 line pairs $/ \mathrm{mm}$ ) was found to be comparable to that of standard Xrays, it produces a reversed image which can prove confusing. Orientation was found to be especially difficult when screening the carpal and tarsal bones.

Table 1

\begin{tabular}{lr}
\hline & \\
Fingers and thumbs & 52 \\
Toes & 21 \\
Hand (soft tissues and metacarpals) & 18 \\
Foot (soft tissues and metatarsals) & 15 \\
Wrist & 8 \\
Forearm & 3 \\
Ankle & 1 \\
& 118 \\
\hline
\end{tabular}

\section{- Reasons for screening}

Table 2

(1) Suspected fracture $\quad 88$

(2) Soft tissue foreign bodies 21

(3) Bony injury of indeterminate nature 6

(4) Suspected dislocations 3

118

In addition to diagnosis, the device was used to monitor the reduction of fractures and dislocations and to assist in locating radio-opaque foreign bodies at operation.

\section{Follow-up X-rays}

During the first week, 21 cases out of $56(38 \%)$ were X-rayed after being screened. 
These X-rays confirmed the initial Lixiscope diagnosis in 13 cases (62\%). In theT remaining eight cases $(38 \%)$ the provisional diagnosis was adjusted in the light of the $\mathrm{X}_{\mathrm{D}}^{\mathrm{B}}$ ray findings.

During the second week, as confidence grew, only 10 of the 62 cases had 'follow-up $\mathrm{X}$-rays; seven $(11 \%)$ of these were taken for reasons of uncertainty over the diagnosis one was taken prior to referral of a patient to another department and three to provide permanent record of successful Colles' fracture manipulations. X-ray finding confirmed the Lixiscope findings in each of the seven cases.

\section{Screening as an alternative to $\mathbf{X}$-rays}

During the second week, the doctors were asked if standard X-rays would have beent $\overrightarrow{\vec{\omega}}$ taken if a Lixiscope had not been available. The response was 'Yes' in 46 cases and 'No in 16 .

\section{Comments from users}

Comments from users

The nine doctors who used the device were unanimous in its praise and quickly became adept in its use.

\section{DISCUSSION}

It was anticipated that the Lixiscope would produce two main benefits.

- To speed up the management of certain categories of patient.

- To reduce the numbers of X-rays ordered.

\section{- Time saved}

$\mathrm{X}$-raying patients takes time. This is never less than about 15 minutes per patient and can be 2 hours or more. Prolonged waiting time is at the root of many complaints againsto the accident and emergency department. The Lixiscope gives the diagnosis in a matter $₹$ of seconds, minimizing the time taken to manage the case and reducing overall waiting 9 time for other patients. This time-saving is particularly noticeable in (a) the location of small foreign bodies and (b) checking the reduction of fractures.

\section{Reduction in numbers of $\mathbf{X}$-ray requests}

The device was found to be useful as an alternative to standard radiography in a number of situations.

(1) Diagnosing the presence or absence of fractures. 
(2) Locating foreign bodies in soft tissues.

(3) Checking reductions of upper-limb fractures.

(4) Positioning screws and wires during fracture fixation.

During the second week $394 \mathrm{X}$-rays were ordered by the accident and emergency department. A further $46(10.5 \%)$ would have been requested had the device not been available. It has been estimated that a hand or foot X-ray costs the National Health Service over $£ 5$, thus the Lixiscope saved a minimum of $£ 230$ in that week (a projected $£ 11960$ per year). The capital cost of the device is thus recovered in less than 9 months.

\section{Safety factors}

The Lixiscope utilized a source of maximum activity $500 \mathrm{mCi}$, although the model tested operated satisfactorily with a source of $200 \mathrm{mCi}$. Scattered irradiation during usage was found to be extremely low, none being measured at the position of the operator's eye or trigger finger. The maximum scatter was measured at an angle of $135^{\circ}$ from the beam direction, that is, away from the observer's face. However, the dosage received would be so low, even with intensive use, that an operator would not need to be designated in terms of Radiation Protection Regulations and would not require personal $80^{\circ}$ monitoring. Care should, however, be exercised by the operators to ensure that their hands and body and the patient's body are kept away from the area of maximum scatter. Tests revealed that even with a source of maximum activity, patients being screened would receive radiation doses of about one half of what would be expected from standard X-rays. It is also advised that adequate lead-shielding be provided for pregnant women being screened.

\section{CONCLUSIONS}

It was felt that the Lixiscope would be extremely useful in the accident and emergency department. It is cost-effective and improves the speed and efficiency of patient management.

\section{ACKNOWLEDGEMENT}

We gratefully acknowledge the assistance given by Mr A. R. Denman and Mr S. J. Evans of the Medical Physics Department, Northampton General Hospital, both during the trial and with the preparation of this report.

R. G. DANIELS* \& M. A. MASON $\dagger$

* Consultant and $†$ Senior Registrar, Accident \& Emergency Department, Northampton General Hospital, Northampton, England 